\title{
Together and apart: inhibition of DNA synthesis by connexin-43 and its relationship to transforming growth factor $\beta$
}

\author{
Maya M. Jeyaraman ${ }^{1,2}$, Robert R. Fandrich ${ }^{1,3}$ and Elissavet Kardami ${ }^{1,2,3 *}$ \\ 1 Institute of Cardiovascular Sciences, St. Boniface Research Centre, University of Manitoba, Winnipeg, MB, Canada \\ 2 Department of Physiology, University of Manitoba, Winnipeg, MB, Canada \\ ${ }^{3}$ Department of Human Anatomy and Cell Sciences, University of Manitoba, Winnipeg, MB, Canada
}

\section{Edited by:}

Stefan Dhein, Universitätsklinik

Leipzig Herzzentrum Leipzig GmbH,

Germany

\section{Reviewed by:}

Marc Chanson, University of Geneva, Switzerland

Stefan Dhein, Universitätsklinik

Leipzig Herzzentrum Leipzig GmbH,

Germany

\section{${ }^{*}$ Correspondence:}

Elissavet Kardami, Institute of Cardiovascular Sciences, St. Boniface Research Centre, University of Manitoba, 351 Taché Avenue, Winnipeg, MB R2H 2A6, Canada e-mail: ekardami@sbrc.ca
The membrane and channel protein connexin-43 (Cx43), as well as the cytokine transforming growth factor (TGF) $\beta$, suppress proliferative growth in cardiomyocytes and other cell types. Previously we showed that the inhibitory effect of $\mathrm{C} \times 43$ is canceled when $\mathrm{C} \times 43$ becomes phosphorylated at serine (S) 262 in response to mitogen stimulation. We have now asked if the TGF $\beta$-triggered inhibition of DNA synthesis is associated with changes in Cx43 phosphorylation at S262. Conversely, we investigated if inhibition of DNA synthesis by overexpressed $\mathrm{C} \times 43$ is dependent on engaging TGF $\beta$ signal transduction. We report that TGF $\beta$ acutely prevented mitogen-induced Cx43 phosphorylation at S262, while chronic inhibition of TGF $\beta$ signal transduction raised baseline levels of endogenous phosphoS262-Cx43 without affecting total $\mathrm{C} \times 43$. Inhibition of baseline TGF $\beta$ signal transduction through (a) inhibiting TGF $\beta$ receptor I (TGF $\beta$ RI) with SB431542, (b) inhibiting TGF $\beta$ receptor II (TGF $\beta$ RII) by overexpressing dominant-negative (DN)TGF $\beta$ RII, (c) inhibiting the downstream signaling mediator Smad2 by overexpressing DN Smad2, each separately increased baseline cardiomyocyte DNA synthesis, but could not reverse DNA synthesis inhibition by overexpressed $\mathrm{C} \times 43$. It is suggested that inhibition of cardiomyocyte DNA synthesis by TGF $\beta / T G F \beta R I / I /$ phospho-Smad2 signaling is mediated, at least in part, by reducing endogenous phospho-S262-Cx43 levels.

Keywords: connexin-43, phosphorylation, cell proliferation, transforming growth factor $\beta$, cardiomyocytes

\section{INTRODUCTION}

Cardiomyocytes, the contractile functional units of the heart pump, are proliferative during the embryonic and early neonatal stages. Subsequently cardiac increases in mass and size occur mainly by increased size of individual myocytes (hypertrophy) rather than cell proliferation (Ahuja et al., 2007). Ischemic heart disease and myocardial infarction cause damage and loss of functional myocardium, which is replaced mainly by scar tissue, resulting in maladaptive remodeling and heart failure. Endogenous capacity for regeneration after extensive injury resulting in cell death is inadequate to replace lost cardiac tissue; nevertheless, a small percentage of adult cardiomyocytes maintain the capacity to enter the cell cycle (Bergmann et al., 2009), and this percentage increases after myocardial infarction (Senyo et al., 2013), indicative of an attempt for a regenerative response. To improve cardiac regeneration after injury it is important to identify factors and mechanisms stimulating or inhibiting cardiomyocyte proliferation. This understanding can provide strategies for stimulating or dis-inhibiting cardiomyocyte proliferation as may be needed during cardiac repair after myocardial infarction.

Overexpression as well as knock-down studies have shown that the membrane and gap junction channel phosphoprotein connexin-43 (Cx43) inhibits DNA synthesis in cardiomyocytes and several other cell types (Doble etal., 2004; Kardami et al.,
2007; Zhang et al., 2008; Matsuyama and Kawahara, 2009). The mechanism by which Cx43 affects cell proliferation includes significant effects on gene expression; and does not require the channel-forming ability of the molecule (Kardami et al., 2007). It is important to note that the ability of $\mathrm{Cx} 43$ to inhibit cell proliferation is regulatable: mitogen-induced phosphorylation of $\mathrm{Cx} 43$, or the C-terminal of $\mathrm{Cx} 43$ (Cx43-CT) at S262, was shown to cancel their inhibitory effect on DNA synthesis (Doble et al., 2004; Dang etal., 2006). Mitogens such as fibroblast growth factor 2 (FGF-2) stimulate cardiomyocyte proliferation, as well as $\mathrm{Cx} 43$ phosphorylation at S262.

The proliferative action of FGF-2 is counteracted by another multifunctional protein, transforming growth factor (TGF) $\beta$, which inhibits cardiomyocyte proliferation (Kardami, 1990; Sheikh etal., 2004). Proliferative growth suppression by $\mathrm{Cx} 43$ may be linked to TGF $\beta$ signaling: $\mathrm{Cx} 43$ was reported to potentiate TGF $\beta$ signaling in the atria-derived cardiomyocyte cell line HL-1, by competing with the downstream mediator of TGF $\beta$ signal transduction, Smad2, for binding to tubulin (Dai et al., 2007). This competitive binding released Smad2 from microtubules, thus making it available for phosphorylation by TGF $\beta$ receptor I (TGFßRI), followed by nuclear translocation, and activation of TGF $\beta$ responsive genes (Dai etal., 2007). In addition, TGF $\beta$ is known to upregulate $\mathrm{Cx} 43$ expression in a number of 
cell types including epithelial cells and vascular smooth muscle cells, and this upregulation may contribute to inhibition of DNA synthesis (Rama et al., 2006; Tacheau et al., 2008).

In the present study, we addressed the potential relationship between Cx43 and TGF $\beta$-mediated inhibition of cardiomyocyte DNA synthesis. Our data showed that TGF $\beta$ signaling inhibited the growth factor-induced phosphorylation of endogenous Cx43 at S262. On the other hand, inhibition of cardiomyocyte DNA synthesis by overexpressed $\mathrm{Cx} 43$ did not require downstream activation of TGF $\beta$-related signals such as TGF $\beta$ RI, TGF $\beta$ RI, or Smad2. Overall our data suggest that Cx43-mediated inhibition is downstream of early TGF $\beta$ signal transduction, and that the mechanism of TGF $\beta$-triggered inhibition of cardiomyocyte DNA synthesis includes downregulation of endogenous pS262-Cx43.

\section{MATERIALS AND METHODS ANIMALS}

One-day-old Sprague Dawley rat pups were obtained from the Central Animal Care Facility at the University of Manitoba. This study was carried out in strict accordance with the recommendations in the Guide for the Care and Use of Laboratory Animals by the US National Institutes of Health (NIH Publication No. 85-23, revised 1996). Approval for use of rat pups was obtained by the Protocol Management and Review Committee of the University of Manitoba.

\section{REAGENTS}

Rabbit polyclonal antibodies recognizing: (i) total Cx43 (phosphorylated as well as unphosphorylated), were raised in-house against a synthetic peptide containing Cx43 residues 367-382; the immune serum was used at 1:10,000 dilution for western blotting, (ii) anti-phospho-(p) 262-Cx43 antibodies were purchased from Santa Cruz Biotechnology (CA, USA), as a $200-\mu \mathrm{g} / \mathrm{ml}$ solution, and were used at 1:1000 dilution. These antibodies have been characterized and described previously (Doble et al., 2004; Srisakuldee et al., 2009). Anti-bromodeoxyuridine (BrdU) antibodies (GE Biosciences) were used at 1:1000 dilution. Antiphospho-(p)Smad2(Ser465/467), or anti-Smad2 antibodies were purchased from Upstate or Cell Signaling Technology (MA, USA), respectively and used at 1:1000 dilution. Mouse monoclonal anti$\alpha$-actinin (1:200) and rabbit anti-actin (1:1000) antibody were from Sigma (USA). Goat anti-mouse and anti-rabbit HRP (horse radish peroxidase) secondary antibodies, were obtained from BioRad (CA, USA) and used as per manufacturer's instructions. The TGFßRI inhibitor SB431542 was purchased from Tocris Bioscience (Bristol, UK). TGF $\beta 1$ was purchased from R\&D Systems (USA), and used at $5 \mathrm{ng} / \mathrm{ml}$. Recombinant $18 \mathrm{kDa}$ FGF-2 was produced in-house as we have described (Jiang et al., 2002, 2004), and used at $10 \mathrm{ng} / \mathrm{ml}$. Adenoviral vectors expressing wild type-Cx43, mutant S262A-Cx43 or truncated Cx43-CT (residues 247-382), have been described previously (Doble et al., 2004; Kardami et al., 2007), and were used at low titers ( 2 m.o.i; multiplicity of infection), achieving modest overexpression, namely a two- to threefold increase in total Cx43 (Srisakuldee et al., 2009). The adenoviral vector expressing TGF $\beta$ RII-dominant-negative (DN) has been described (Sheikh et al., 2004) and was used at 50 m.o.i. Adenoviral vectors expressing DN Smad2-DN, or Smad3-DN have been described in
(Uemura et al., 2005) and were generous gifts from Dr. Rebecca Wells (University of Pennsylvania School of Medicine, PA, USA); they were used at 100 m.o.i.

\section{WESTERN BLOT ANALYSIS}

Lysates were analyzed on $10 \%$ polyacrylamide gels, at $10 \mu \mathrm{g}$ protein/lane, as described previously (Srisakuldee et al., 2009). Broad range (6.5-200 kDa) molecular mass standards (Bio-Rad) were used in all analyses. Protein concentration was determined by the bicinchoninic acid (BCA) protein assay reagent (Pierce) followed by spectrophotometry. The proteins on the gel were electrophoretically transferred to polyvinylidene difluoride membranes. Antigen-antibody complexes were visualized using enhanced chemiluminescence (ECLplus), from Amersham Pharmacia. Densities of western blot bands were determined using the Bio-Rad Model GS-800 densitometer with Molecular Analyst software (Bio-Rad). Band densities were adjusted based on the density of corresponding loading controls.

\section{NEONATAL RAT VENTRICULAR MYOCYTE CULTURES}

Cardiomyocytes were isolated from the ventricles of 1-day-old rat pups according to standard procedures (Doble et al., 1996). For studies on DNA synthesis, myocytes were plated on collagencoated coverslips at 400,000 cells $/ 35 \mathrm{~mm}$ well, in the presence of $10 \%$ bovine calf serum supplemented with FGF-2 $(10 \mathrm{ng} / \mathrm{ml})$ and routinely maintained in this type of medium in experiments using adenoviral vector gene transfer. In some experiments, myocytes were placed in a low serum medium ( $0.5 \%$ bovine calf serum supplemented with $0.5 \%$ bovine serum albumin (BSA), $1 \%$ penicillin/streptomycin, $0.04 \%$ vitamin C, $0.1 \%$ insulin, $0.1 \%$ transferrin/selenium) for $48 \mathrm{~h}$, followed by stimulation with FGF$2(10 \mathrm{ng} / \mathrm{ml}, 30 \mathrm{~min})$ in the presence or absence of $15 \mathrm{~min}$ pre-treatment with TGF $\beta(5 \mathrm{ng} / \mathrm{ml})$.

\section{BROMODEOXYURIDINE LABELING INDEX}

As described previously (Doble et al., 2004). Briefly, cardiomyocytes cultured on coverslips were incubated with BrdU $(3 \mu \mathrm{g} / \mathrm{ml})$ for $8-12 \mathrm{~h}$ prior to the termination of various experiments. Coverslips were then fixed with $1 \%$ paraformaldehyde for $15 \mathrm{~min}$ in the cold, and then treated with $0.07 \mathrm{M} \mathrm{NaOH}$ for $2 \mathrm{~min}$ at room temperature. Labeling for sarcomeric $\alpha$-actinin (exclusively cytosolic as well as cardiomyocyte-specific), for BrdU (to identify nuclei synthesizing DNA), and Cx43 (to ascertain Cx43 overexpression after transfection) was achieved using mouse monoclonal antibodies against $\alpha$-actinin, against BrdU, and rabbit polyclonal antibodies against $\mathrm{Cx} 43$. Coverslips were also counterstained for DNA, with Hoechst 33342. A minimum of 24 randomly selected visual fields, distributed in three coverslips, were observed under epifluorescence optics, photographed, and individually scored for numbers of BrdU-positive cardiomyocyte nuclei, over total cardiomyocyte nuclei (BrdU labeling index).

\section{STATISTICS}

The GraphpadStat and SigmaStat software programs were used for data analysis. Data are presented as mean \pm SEM (standard error of the mean). Statistical analysis was performed using either one-way ANOVA to compare more than two groups or two-way 
ANOVA to compare more than two groups with two independent variables. $P<0.05$ was considered statistically significant. $P<0.01$ was considered statistically very significant.

\section{RESULTS}

\section{EFFECT OF TGF $\beta$ ON RELATIVE CARDIOMYOCYTE pS262-Cx43 LEVELS}

Our previous studies have demonstrated that cardiomyocytes maintained in culture under growth-stimulating conditions, are nevertheless subjected to a degree of mitotic suppression by "baseline TGF $\beta$," representing TGF $\beta$ present in serum, and/or made by myocytes and the small amount of contaminating fibroblasts, in culture. Inhibiting this baseline TGF $\beta$ signaling potentiated the ability of growth factors such as FGF-2 to stimulate cardiomyocyte proliferation (Doble et al., 2004; Sheikh et al., 2004). As we have found a positive relationship between growth factor-induced Cx43 phosphorylation at S262, and the ability of growth factors to stimulate cardiomyocyte proliferation, we asked whether inhibition of baseline TGF $\beta$ signal transduction would influence levels of endogenous pS262-Cx43, in culture.

Primary cultures of neonatal cardiac myocytes, placed under conditions stimulating proliferative growth $(10 \%$ bovine calf serum, plus $10 \mathrm{ng} / \mathrm{ml}$ FGF-2) were exposed to a pharmacological inhibitor of TGF $\beta$ RI (SB431542), or subjected to overexpression of DN versions of either TGF $\beta$ RII or Smad2, through adenovirally mediated transient gene transfer. One day following these manipulations cell lysates were analyzed for total as well as pS262-Cx43 by western blotting. Two types of control cultures were used: in the first, cells were kept in growth medium without any treatment, while in the second cells were treated with an empty adenoviral vector. As shown in Figure 1, both types of controls elicited signals of similar intensity for pS262-Cx43, as well as total $\mathrm{Cx} 43$, indicating that the adenoviral vector had no effect on $\mathrm{Cx} 43$. Treatment

A
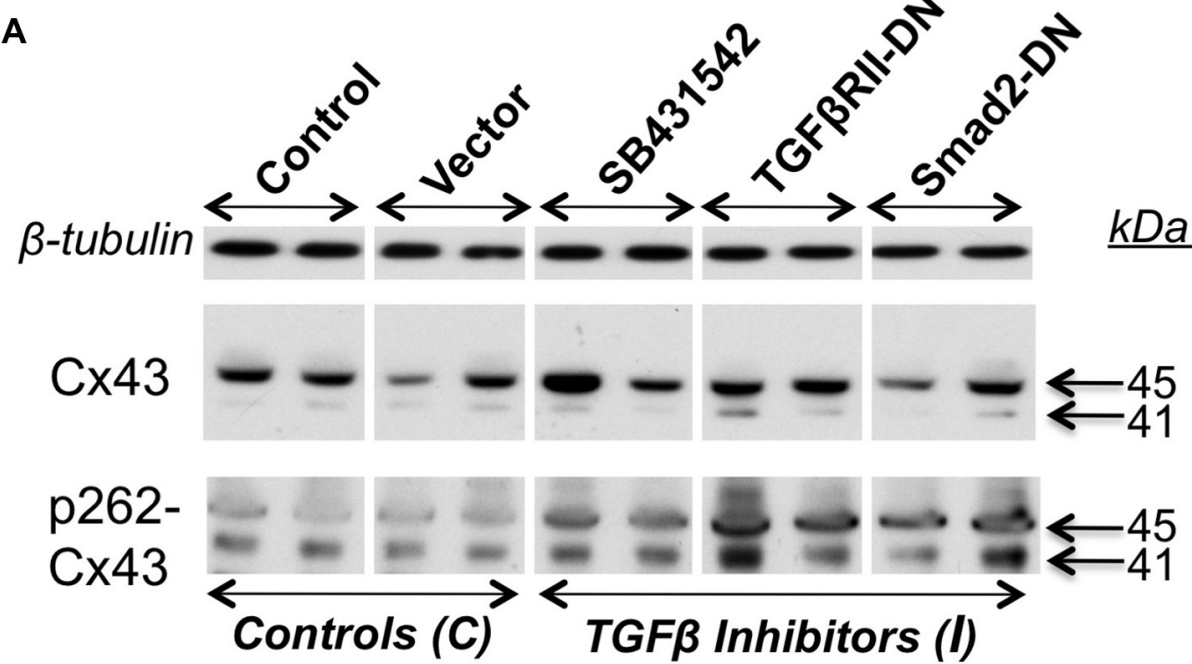

B
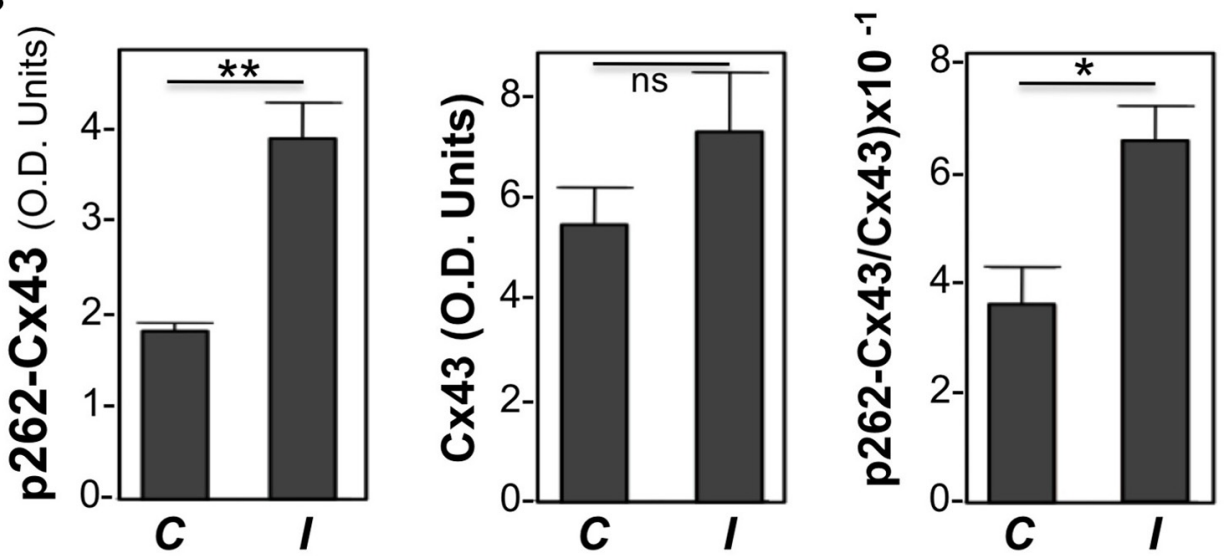

FIGURE 1 | Inhibition of TGF $\beta$ signaling increases baseline cardiomyocyte Cx43 phosphorylation at S262. (A) Western blots of cardiomyocyte lysates probed for total Cx43 (Cx43), pS262-Cx43, and $\beta$-tubulin (loading control), as indicated. Samples shown represent five groups, including two types of controls (C), such as myocytes subjected to no treatment (Control), or exposed to an empty adenoviral vector (Vector); the two controls produced similar data. The remaining three groups were treated with TGF $\beta$ signaling inhibitors (I), such as SB431542 (20 $\mu \mathrm{M})$ and adenoviral vectors expressing TGF $\beta$ RII-DN or Smad2-DN, as indicated. All three groups showed increased signal for pS262-Cx43, compared to control groups. (B) Combined densitometry data (optical density, OD units) comparing relative pS262-Cx43, total $\mathrm{C} \times 43$, or the ratio of $\mathrm{pS} 262-\mathrm{C} \times 43 /$ total $\mathrm{C} \times 43$ between control, $C(n=4)$, and $I$-treated groups $(n=6)$. ${ }^{*}{ }^{*},{ }^{*}$, and ns denote $P<0.01, P<0.05$, and $P<0.05$. 
of cardiomyocytes with inhibitors of TGF $\beta$ signal transduction elicited a significant increase in pS262-Cx43 (Figure 1), but had no significant effect on total $\mathrm{Cx} 43$.

Probing with antibodies recognizing total $\mathrm{Cx} 43$ showed that the majority of $\mathrm{Cx} 43$ migrated at $45 \mathrm{kDa}$, representing extensively phosphorylated $\mathrm{Cx} 43$, with a faint signal near $41 \mathrm{kDa}$, representing unphosphorylated or minimally phosphorylated $\mathrm{Cx} 43$. This pattern is typical for cardiomyocytes (Doble et al., 2004; Srisakuldee et al., 2009). Probing with anti-pS262-Cx43 detected bands migrating near 41 as well as $45 \mathrm{kDa}$, indicating that, under "growth stimulation" conditions, phosphorylation at the S262 site can occur, respectively, on Cx43 that lacks substantial phosphorylation at other sites, as well as on $\mathrm{Cx} 43$ extensively phosphorylated at other sites. Please note that any shift in motility that might be caused by phosphorylation at a single site (S262) would not be detectable by standard one-dimensional electrophoresis as used here. Inhibition of TGF $\beta$ signal transduction upregulated both the faster and slower migrating pS262-Cx43 bands. Figure 1B is showing densitometric results representing the sum of $\mathrm{Cx} 43$ or pS262-Cx43 bands.

In another experiment, we tested the effect of TGF $\beta$ on the acute FGF-2-induced stimulation of $\mathrm{Cx} 43$ phosphorylation at S262. To minimize baseline protein kinase C (PKC) activity, and thus baseline levels of pS262-Cx43, cardiomyocytes were kept in low serum $(0.5 \%$ fetal bovine serum) for $48 \mathrm{~h}$ before stimulation, as described previously (Doble et al., 2004). Myocytes were then subjected or not to a brief 15-min pre-incubation with TGF $\beta$ $(5 \mathrm{ng} / \mathrm{ml})$, and then stimulated with FGF-2 (10 ng/ml) for $30 \mathrm{~min}$. FGF-2 significantly increased the anti-pS262-Cx43 signal, migrating at $45 \mathrm{kDa}$, in the absence of TGF $\beta$ pre-treatment, as expected from previous studies (Doble et al., 2004); Figure 2. The stimulatory effect of FGF-2 was, however, completely prevented in cells pre-treated with TGF $\beta$; Figure 2. The faster migrating pS262Cx43 observed in the previous experiment (Figure 1) was not detectable in cultures kept in low serum and may be a characteristic of cultures grown under conditions promoting proliferative growth.

\section{EFFECT OF INHIBITION OF TGF $\beta$ SIGNAL TRANSDUCTION ON GROWTH SUPPRESSION BY OVEREXPRESSED CX43}

To examine the hypothesis that growth suppression by $\mathrm{Cx} 43$ is mediated by downstream activation of TGF $\beta$ signal transduction, cardiomyocyte cultures were subjected to $\mathrm{Cx} 43$ or $\mathrm{Cx} 43-\mathrm{CT}$ overexpression, in a background of pharmacological (SB431542) TGF $\beta$ RI inhibition. BrdU labeling index (proportion of cardiomyocyte nuclei incorporating BrdU, over total number of cardiomyocyte nuclei) was determined 2 days later, as a measure of relative DNA synthesis ability. We have established in previous studies that cardiomyocyte labeling index determinations are mirrored by, and are therefore representative of, cell number determinations (Kardami, 1990; Pasumarthi et al., 1996). The BrdU labeling index of control groups, maintained in growth-stimulating conditions (FGF-2-supplemented serum), varied between 0.25 and 0.30 in different primary cardiomyocyte preparations.

Figure 3A compares normalized BrdU labeling index between the various groups, where the value for the control group, subjected to treatment with an empty adenoviral vector (Vector),

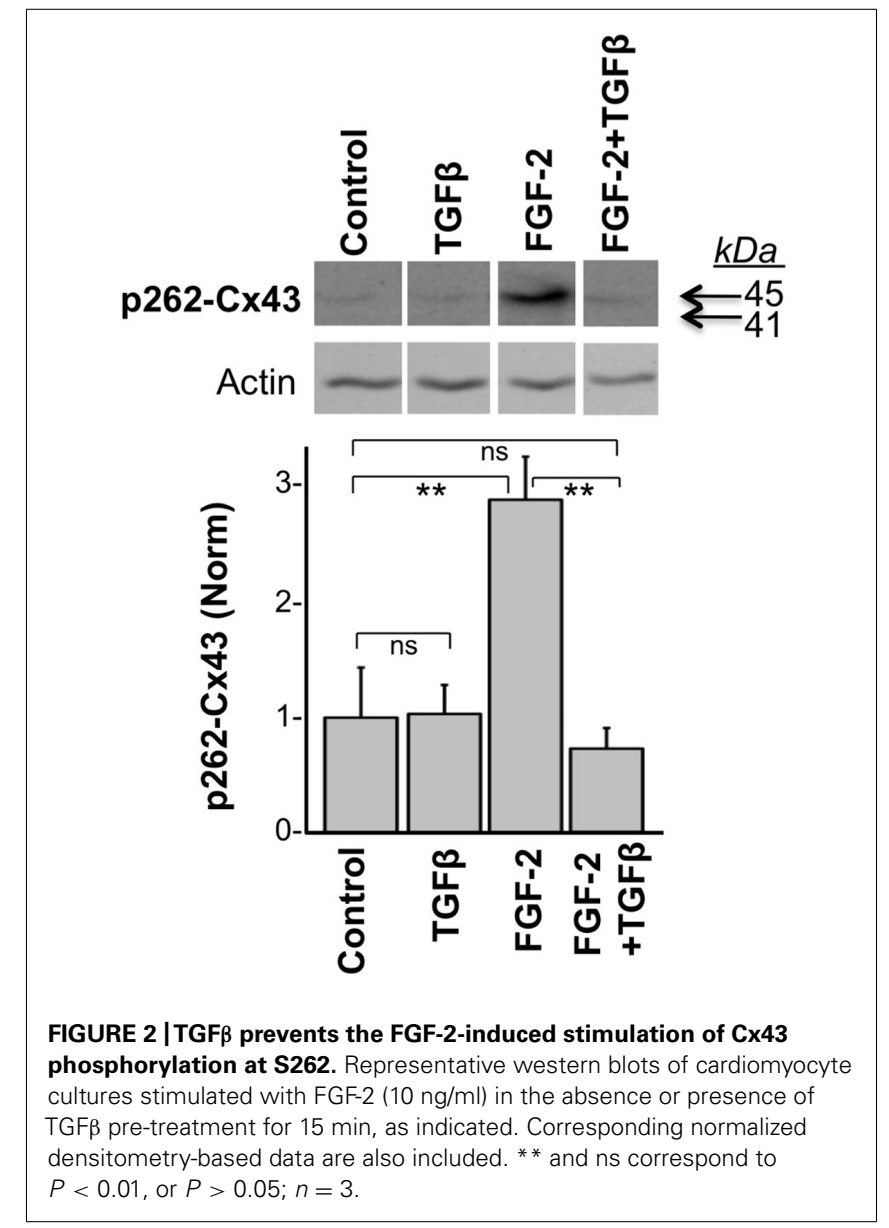

was arbitrarily defined as 1 . In the absence of $\mathrm{Cx} 43$ or $\mathrm{Cx} 43$ CT overexpression, inhibition of TGF $\beta$ RI by SB431542 elicited a significant increase in $\mathrm{BrdU}$ incorporation $(P<0.05)$, as anticipated from successful inhibition of baseline TGF $\beta$ signal transduction (Sheikh et al., 2004). In the absence of SB431542, overexpression of $\mathrm{Cx} 43$, or $\mathrm{Cx} 43-\mathrm{CT}$ elicited a robust inhibition of cardiomyocyte BrdU labeling index, compared to Vector-treated controls, in agreement with our previous report that inhibition of cardiomyocyte DNA synthesis by Cx43 does not require the channel-forming portion of the molecule (Kardami et al., 2007). The presence of SB431542 was unable to reverse/prevent the inhibitory effects of $\mathrm{Cx} 43$, or Cx43-CT overexpression, indicating that suppression of DNA synthesis by $\mathrm{Cx} 43$, or Cx43-CT overexpression does not depend on activation of TGF $\beta$ RI. In fact it would appear that $\mathrm{Cx} 43$, or $\mathrm{Cx} 43-\mathrm{CT}$, overexpression, blocked the ability of SB431542 to increase baseline cardiomyocyte DNA synthesis. This suggested the possibility that $\mathrm{Cx} 43$ overexpression may have somehow blunted the ability of SB431542 to inhibit TGFßRI. If that were the case, SB431542 would not be able to prevent the downstream phosphorylation and activation of Smad2 (pSmad2). We therefore tested the status of Smad2 activation (pSmad2, phosphorylated at serines 465/467) in response to SB431542, Cx43-, Cx43-CT, and a Cx43 phosphorylation mutant (S262A-Cx43). Representative data are shown in Figure 3B. SB431542 eliminated baseline Smad2/3 activation under control 


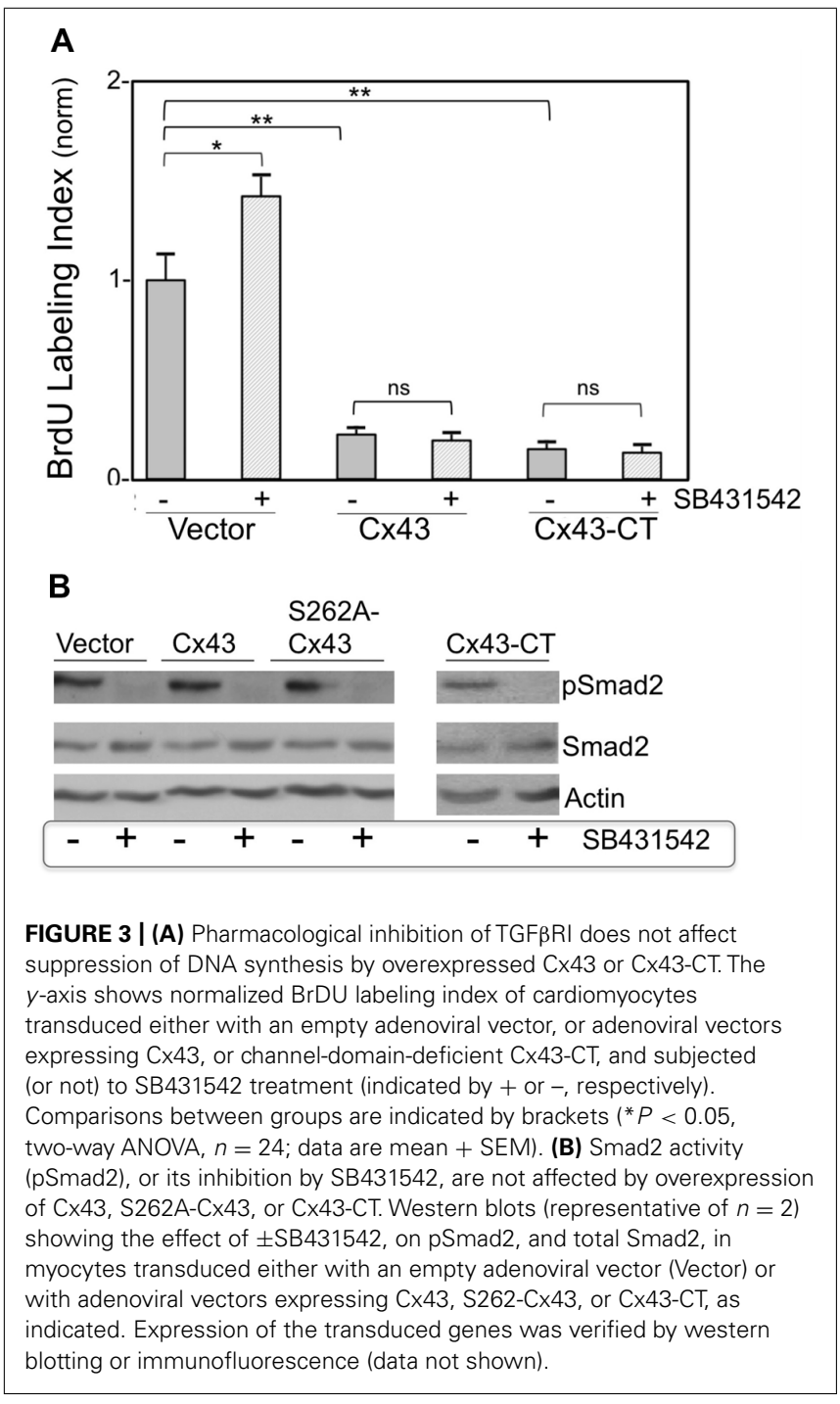

conditions, validating its ability to block downstream TGF $\beta$ TGFR1 signal transduction. The ability of SB431542 to prevent baseline Smad2/3 activation was maintained in the presence of Cx43, Cx43-CT, and S262A-Cx43 overexpression. Furthermore, none of the overexpressed proteins (Cx43, Cx43-CT, S262A-Cx43) appeared to affect baseline levels of $\mathrm{pSmad} 2 / 3$; no discernible changes were observed in total $\mathrm{Smad} 2 / 3$ in any of the groups tested.

The effect of directly inhibiting Smad2 (by expressing a cDNA for Smad2-DN) on cardiomyocyte BrdU labeling index, in the absence or presence of $\mathrm{Cx} 43$ or S262A-Cx43 overexpression, was also examined. Expression of Smad2-DN significantly increased cardiomyocyte labeling index over control cells (Figure 4A). As expected, expression of S262A-Cx43 decreased BrdU incorporation significantly compared to controls; expression of wild type Cx43 exerts a similar inhibitory effect (Figure 3A). The effect of S262A-Cx43, as well as wild type Cx43 remained unchanged in the presence of Smad2-DN (Figure 4A and unpublished observations). The inability of Smad2-DN to reverse the inhibitory effect of S262A-Cx43 may be linked to the inability of the mutant

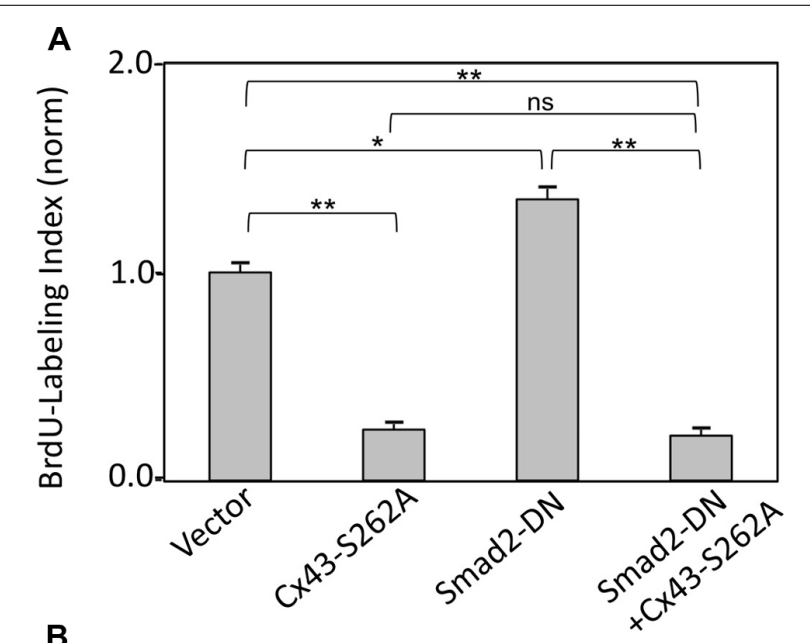

B

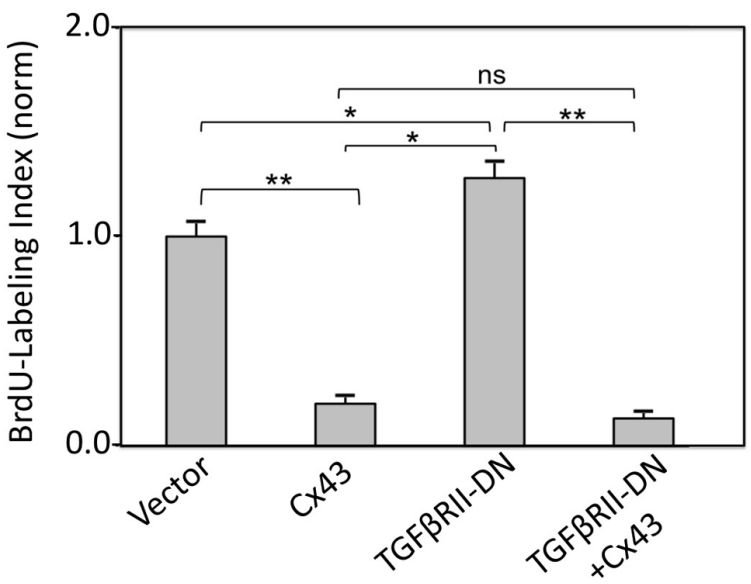

FIGURE 4 | (A) Inhibition of TGF $\beta$ RIII does not affect suppression of DNA synthesis by $\mathrm{C} \times 43$ overexpression. The $y$-axis shows normalized $\mathrm{BrdU}$ labeling index of cardiomyocytes transduced with an empty adenoviral vector (Vector) or adenoviral vectors expressing Cx43, TGFBRII-DN, alone or in combination, as indicated. (B) Inhibition of Smad2 does not affect suppression of DNA synthesis by overexpressed S262A-Cx43. The $y$-axis shows normalized BrdU labeling index of cardiomyocytes transduced with an empty adenoviral vector (vector) or adenoviral vectors expressing S262A-Cx43, or Smad2-DN, or a combination of both. Data are shown as mean + SEM; brackets indicate comparisons between groups. **, *, and ns correspond to $P<0.01, P<0.05, P>0.05$. Expression of the transduced genes was verified by western blotting (data not shown).

Cx43 to become phosphorylated at amino-acid 262, providing an irreversible signal.

Inhibition of TGF $\beta$ RII by overexpressing TGF $\beta$ RII-DN significantly increased BrdU labeling index in cardiomyocytes, as we reported previously (Sheikh et al., 2004). This effect was prevented in the presence of $\mathrm{Cx} 43$ overexpression (Figure 4B).

Taken together, our findings with inhibitors of early TGF $\beta$ signal transduction are consistent with a scenario where $\mathrm{Cx} 43$ mediated growth suppression occurs downstream of TGF $\beta$ / TGFßRII/TGF $\beta$ RI/pSmad2 signaling.

Finally we asked if inhibition of cardiomyocyte DNA synthesis by $\mathrm{Cx} 43$ was additive to that by TGF $\beta$. As shown in Figure 5, addition of TGF $\beta$ or overexpression of $\mathrm{Cx} 43$, both exerted a 


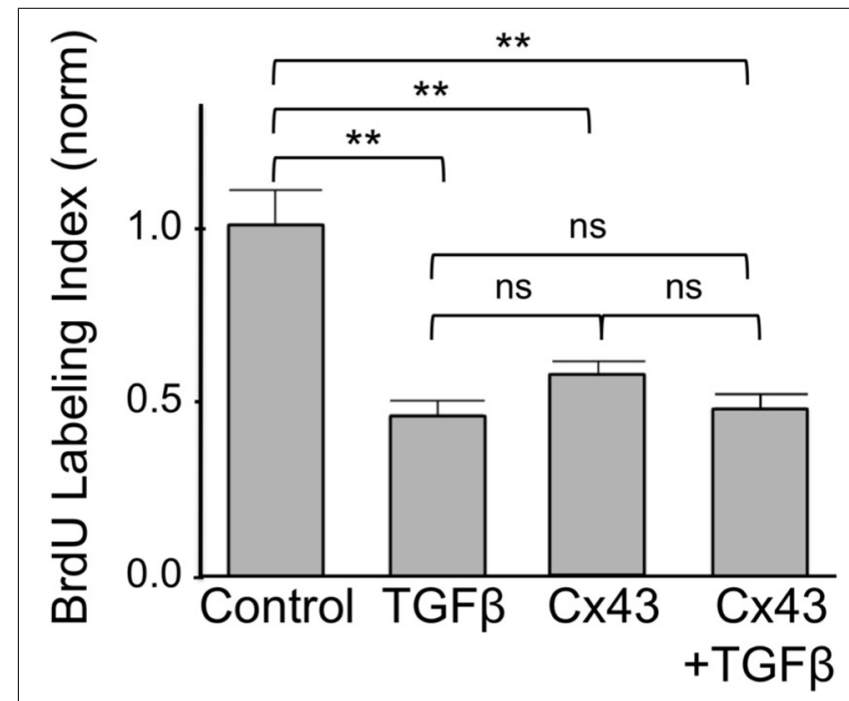

FIGURE 5 | Suppression of DNA synthesis by Cx43 overexpression is not additive to that by TGF $\boldsymbol{\beta}$. The $y$-axis shows normalized BrdU labeling index of untreated cardiomyocytes (Control); cardiomyocytes treated with TGF $\beta$; subjected to $\mathrm{C} \times 43$ overexpression; or treated with TGF $\beta$ in the presence of $\mathrm{C} \times 43$ overexpression, as indicated. Absolute BrdU labeling index was at 0.3. Data are shown as mean \pm SEM. Brackets show comparisons between groups. ${ }^{*}$ and ns correspond to $P<0.01$, or $P>0.05$.

significant inhibitory effect on BrdU labeling index, assessed 1 day after treatment. The degree of inhibition by TGF $\beta$ was not significantly different to that by $\mathrm{Cx} 43$. The extent of inhibition of BrdU incorporation by combined use of TGF $\beta$ and $\mathrm{Cx} 43$ overexpression was not significantly different to that of either inhibitor alone. The absence of an additive effect on DNA synthesis inhibition suggests that TGF $\beta$-triggered signals, and Cx43-mediated signals, are components of the same pathway, where, as indicated by our results shown in the previous Figures (1-5), Cx43-triggered signals are downstream of early TGF $\beta$ signal transduction.

Experimental evidence presented here in combination with previous work pointed to a hypothetical scenario where phosphorylation of $\mathrm{Cx} 43$ at S262 allows this protein to act as a switch between pro-mitotic and anti-mitotic signaling, as illustrated in Figure 6.

\section{DISCUSSION}

Connexin-43 is constitutively phosphorylated at multiple sites, ensuring correct trafficking of this protein to the plasma membrane as well as assembly of connexons and channel functionality (Solan and Lampe, 2009). In addition to the constitutively phosphorylated sites, specific sites at the C-terminal tail of $\mathrm{Cx} 43$ can become phosphorylated in response to growth factor- or oncogene-linked signaling, preventing $\mathrm{Cx} 43$ from suppressing cell proliferation. For example, the src-targeted tyrosines 247 and 265 can affect the ability of Cx43 to inhibit proliferation of glioma cells (Herrero-Gonzalez et al., 2010); serines 255, 262, 279, 282 are reported as targets of mitogen-activated protein kinase pathways, and, their phosphorylation allows for platelet-derived growth factor-triggered mitotic stimulation of vascular smooth

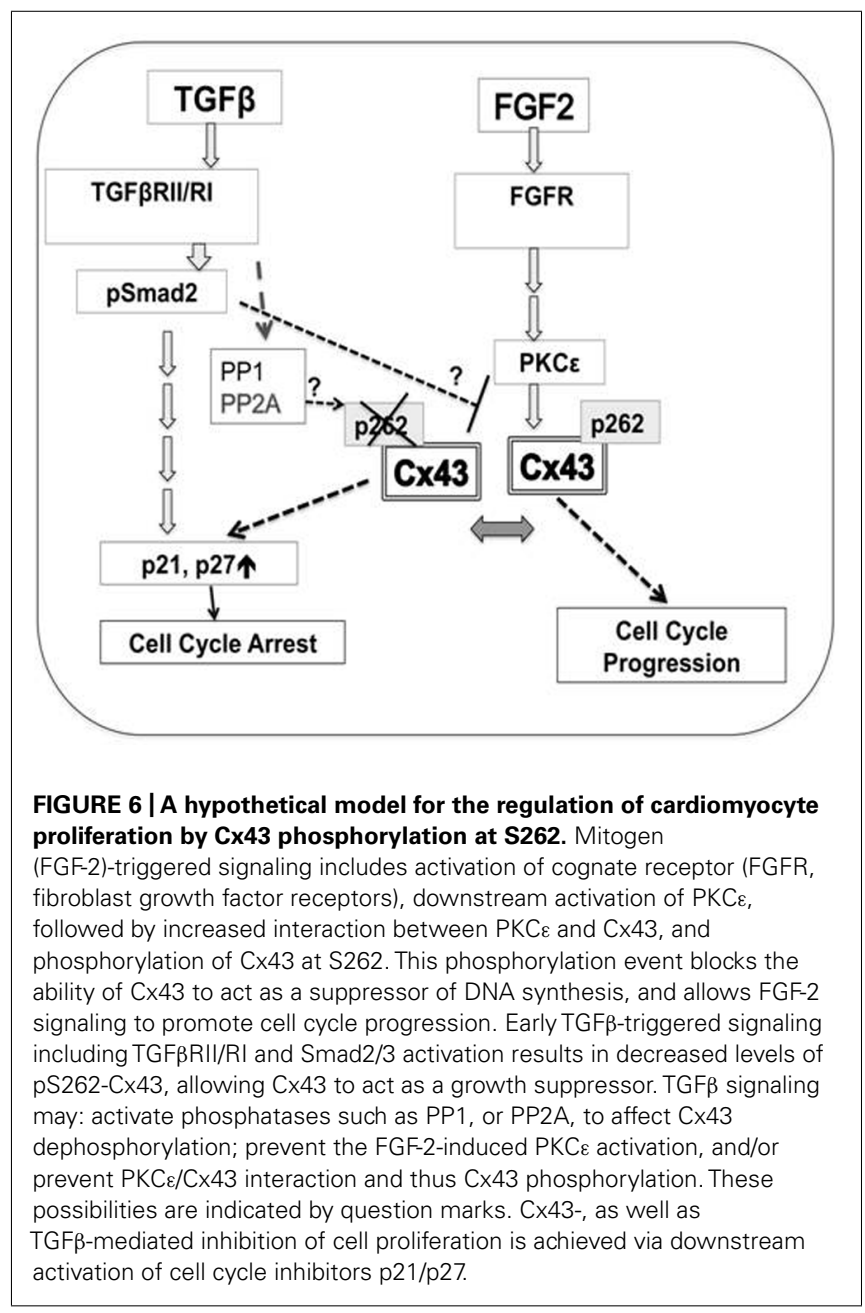

muscle cells (Johnstone etal., 2012). In cardiomyocytes, the FGF-2-induced mitotic stimulation is accompanied by increased phosphorylation of Cx43 at S262, mediated by PKC $\varepsilon$ (Doble et al., 2000, 2004). To understand the role of phosphorylation at S262 on the ability of $\mathrm{Cx} 43$ to suppress growth, in previous studies we used Cx43 phosphorylation mutants to simulate either constitutive phosphorylation (S262-to-aspartate (D) substitution) or lack of phosphorylation (S262A) at the S262 site. The ability of Cx43 to suppress DNA synthesis was found to be maximal in cells expressing S262A-Cx43 but absent in cells expressing S262D-Cx43 (Doble et al., 2004; Dang et al., 2006). Overall our previous work indicated that pS262-Cx43 is "permissive" for DNA synthesis, allowing cells to progress through the cell cycle in response to growth factor stimulation. One may therefore consider the notion that conditions and factors known to inhibit cell proliferation may actively prevent the phosphorylation of $\mathrm{Cx} 43$ at specific sites. TGF $\beta$ is one such factor, known for its cytostatic properties in many situations (Massague, 2000). Because TGF $\beta$ signaling counteracts the stimulatory effect of FGF-2 on cardiomyocytes DNA synthesis (Kardami, 1990), we hypothesized that TGF $\beta$ may promote the "growth inhibitory" state of $\mathrm{Cx} 43$, by preventing its phosphorylation at S262. This question was addressed in both an acute as well as a more "chronic" setting, in culture. 
In the acute setting, a brief pre-treatment with TGF $\beta$ rendered cardiomyocytes incapable of responding to FGF-2 as shown by their blunted ability to upregulate pS262-Cx43; the acute response has "chronic" consequences as it is accompanied by a blunted DNA synthesis and cell proliferation response (Kardami, 1990); see also Figure 5. In a more "chronic" scenario, we tested the consequences of inhibiting constitutive TGF $\beta$ signal transduction on endogenous pS262-Cx43 levels. The biological effects of TGF $\beta$ are transduced by binding to plasma membrane receptors, TGF $\beta$ RII and TGF $\beta R$ I, downstream activation/phosphorylation of the regulatory Smads (Smad2 and Smad3), their interaction with Smad4, nuclear translocation and activation of specific gene expression (Massague and Wotton, 2000; Heldin et al., 2009). Inhibition at the level of TGF $\beta$ R1 was achieved through the use of SB431542, which inhibits TGFRI (ALK5) by acting as a competitive ATP binding site kinase inhibitor (Inman et al., 2002). In cardiomyocytes, which express ALK5, SB431542 is effective in preventing downstream activation (phosphorylation) of Smad2 as shown by (Waghabi et al., 2002), and confirmed here. To specifically target the activity of TGF $\beta$ RII, which acts as a co-receptor with TGF $\beta$ RI, we overexpressed a kinase-deficient TGF $\beta$ RII which has been shown to be effective in inhibiting endogenous TGF $\beta$ RII in a DN fashion (Sheikh et al., 2004). Finally, Smad2 activation (phosphorylation) was prevented by overexpressing Smad2-DN. All of these inhibitors increased endogenous levels of pS262-Cx43, without affecting total $\mathrm{Cx} 43$ protein levels, indicating that early TGF $\beta$ signal transduction (engaging the activity of TGF $\beta$ RII and TGF $\beta$ RI and resulting in Smad2 phosphorylation) downregulates pS262Cx43. This may occur by: directly preventing the FGF-2-induced activation of $\mathrm{PKC} \varepsilon$ which acts as an upstream phosphorylating kinase for $\mathrm{Cx} 43$; by preventing $\mathrm{Cx} 43$ interaction and/or phosphorylation by the $\mathrm{PKC} \varepsilon$; by activating phosphatase(s) that would cause Cx43 dephosphorylation. There is evidence to support the latter possibility: TGF $\beta$ signaling activates protein phosphatase (PP)-2A (Petritsch et al., 2000), which has been reported to target Cx43 for dephosphorylation (Ai et al., 2011). Other potential phosphatases implicated in $\mathrm{Cx} 43$ dephosphorylation include PP1 and PP2B (Jeyaraman et al., 2003). There is at present limited information as to potential effects of TGF $\beta$ on PKC $\varepsilon$ activity or expression, or on the $\mathrm{PKC} \varepsilon / \mathrm{Cx} 43$ interaction. It is of interest, however, that $\mathrm{PKC} \varepsilon$ is promoting the proliferation of cells, including cardiomyocytes (Kardami et al., 2003), and has an antithetical relationship with TGF $\beta$ regarding the control of CD4 ${ }^{+}$T-lymphocyte proliferation (Mirandola et al., 2011).

In parallel to increasing endogenous pS262-Cx43, inhibition of constitutive TGF $\beta$ signal transduction increased cardiomyocyte DNA synthesis, providing further validation to the notion that Cx43 phosphorylation at S262 is permissive for mitogenic stimulation. It should, however, be noted that inhibition of constitutive TGF $\beta$ signal transduction was unable to reverse the inhibitory effects of overexpressed $\mathrm{Cx} 43$. It is possible that overexpressed Cx43 (or Cx43-CT) overwhelm the endogenous cellular machinery (kinases/phosphatases) affected by inhibition of baseline TGF $\beta$ signaling. In broad agreement with this notion, we have previously observed that only a small fraction of overexpressed $\mathrm{Cx} 43$, or Cx43-CT, become phosphorylated at S262 under normal culture conditions, requiring stimulation with a highly potent $\mathrm{PKC}$ activator, phorbol-12-myristate-13-acetate, for $\mathrm{Cx} 43$ to become mostly phosphorylated at that site (Dang et al., 2006). A likely explanation therefore for the apparent discrepancy of our findings with endogenous versus overexpressed $\mathrm{Cx} 43$ is that any signals (kinases/phosphatases) activated or dis-inhibited by blocking baseline TGF $\beta$ signaling may be inadequate to promote or sustain substantial phosphorylation at S262 when Cx43 is present at above-normal levels.

Previous studies using a cardiac cell line, atria-derived HL-1, indicated that $\mathrm{Cx} 43$, of unknown phosphorylation status, activated TGF $\beta$ transcriptional activity, by activating TGF $\beta$ RI, and promoting Smad2/3 phosphorylation and nuclear translocation; it was suggested that $\mathrm{Cx} 43$-dependent suppression of cardiomyocyte proliferative growth reflected downstream activation of Smad2/3 (Dai et al., 2007). This would position Cx43 expression upstream of TGF $\beta$ RI-pSmad 2 signal transduction, in apparent contrast to findings presented here. We showed that ectopic expression of Cx43 inhibited DNA synthesis regardless of the status of TGF $\beta$ RI or Smad2/3 activation; in addition neither $\mathrm{Cx} 43$ nor Cx43-CT overexpression had any discernible effect on relative $\mathrm{pSmad} 2$ levels in our system. Our data therefore suggested that Cx43-mediated inhibition of DNA synthesis is not mediated by downstream activation of TGF $\beta$ signals. It is possible that these differences may reflect differences between experimental approaches (gainof-function in the case of overexpression versus loss-of-function in knock-down studies) and/or cell types, namely the mouse atrial HL-1 cell line versus rat primary ventricular cardiomyocytes used here. Also, as Dai et al. (2007) used TGF $\beta$ transcriptional activation as their end-point, there was no information as to how the observed Smad2/3 and/or Cx43 expression changes affected DNA synthesis in their system.

The precise molecular mechanism by which $\mathrm{Cx} 43$ and pS262$\mathrm{Cx} 43$ affect proliferative growth remains to be determined. The role of subcellular localization of $\mathrm{Cx} 43$ is not clear: Cx43-CT, which, unlike $\mathrm{Cx} 43$, localizes to the cytosol and nucleus, retains inhibitory activity (Dang et al., 2003; Kardami et al., 2007), suggesting that localization at cell-cell contact sites and/or gap junction function are not crucial determinants of growth inhibitory activity. Furthermore, phosphorylation at S262 (simulated by expression of S262D-Cx43, or -Cx43-CT) blocked the inhibitory properties of not only $\mathrm{Cx} 43$ but also Cx43-CT, without affecting their respective distinct localizations, at plasma membrane versus cytosolic/nuclear sites, in HEK293 cells; unpublished observations and as shown previously (Dang et al., 2003, 2006). It is of interest, however, that Cx43 (Boengler et al., 2005) as well as a C-terminal containing fragment of Cx43 (Kardami et al., 2007) have also been detected in cardiac mitochondria. Mitochondria play an important role in cell cycle regulation (Antico Arciuch et al., 2012), and therefore future studies should examine whether mitochondrial Cx43, and its potential phosphorylation at S262, modulate mitochondrial function in this context.

In conclusion, our studies suggest the following model to describe the relationship between TGF $\beta$ and Cx43-mediated growth suppression in cardiomyocytes; Figure 6. TGF $\beta$-triggered early signal transduction, involving activation of TGF $\beta$ RII/RI and phosphorylation of Smad2, reduces relative levels of pS262-Cx43, by either preventing the growth factor-induced $\mathrm{PKC} \varepsilon$ activation, 
or $\mathrm{PKC} \varepsilon / \mathrm{Cx} 43$ interaction, and/or by activating $\mathrm{Cx} 43$-targeting phosphatase(s). Cx43 lacking phosphorylation at S262 possesses growth inhibitory activity, blocks growth factor (FGF-2) signals from stimulating cell cycle progression, and mediates or at least contributes to inhibition of DNA synthesis by TGF $\beta$. It has been established that both TGF $\beta$-, and Cx43-, mediated suppression of cell proliferation are achieved by upregulating the cyclin-dependent kinase inhibitors p21/p27 which control cell cycle arrest (Sanchez-Alvarez et al., 2006; Abbas and Dutta, 2009; Bauer etal., 2012), and thus these signals are proposed to be activated downstream of $\mathrm{Cx} 43$ lacking phosphorylation at S262. Mitogens, such as FGF-2, overcome/attenuate inhibition of DNA synthesis by $\mathrm{Cx} 43$ by promoting activation of $\mathrm{PKC} \varepsilon$ which interacts with, and phosphorylates Cx43 at S262. The ability of FGF-2 to

\section{REFERENCES}

Abbas, T., and Dutta, A. (2009). p21 in cancer: intricate networks and multiple activities. Nat. Rev. Cancer 9, 400-414. doi: 10.1038/nrc2657

Ahuja, P., Sdek, P., and Maclellan, W. R. (2007). Cardiac myocyte cell cycle control in development, disease, and regeneration. Physiol. Rev. 87, 521-544. doi: 10.1152/physrev. 00032.2006

Ai, X., Jiang, A., Ke, Y., Solaro, R. J., and Pogwizd, S. M. (2011). Enhanced activation of p21-activated kinase 1 in heart failure contributes to dephosphorylation of connexin 43. Cardiovasc. Res. 92, 106-114. doi: $10.1093 / \mathrm{cvr} / \mathrm{cvr} 163$

Antico Arciuch, V. G., Elguero, M. E., Poderoso, J. J., and Carreras, M. C. (2012). Mitochondrial regulation of cell cycle and proliferation. Antioxid. Redox Signal. 16, 1150-1180. doi: 10.1089/ars.2011.4085

Bauer, J., Sporn, J. C., Cabral, J., Gomez, J., and Jung, B. (2012). Effects of activin and TGF $\beta$ on p21 in colon cancer. PLoS ONE 7:e39381. doi: 10.1371/journal.pone.0039381

Bergmann, O., Bhardwaj, R. D. Bernard, S., Zdunek, S., BarnabeHeider, F., Walsh, S., et al. (2009). Evidence for cardiomyocyte renewal in humans. Science 324, 98-102. doi: 10.1126/science. 1164680

Boengler, K., Dodoni, G., RodriguezSinovas, A., Cabestrero, A., Ruiz-Meana, M., Gres, P., et al. (2005). Connexin 43 in cardiomyocyte mitochondria and its increase by ischemic preconditioning. Cardiovasc. Res. 67, 234-244. doi: 10.1016/j. cardiores.2005.04.014

Dai, P., Nakagami, T., Tanaka, H., Hitomi, T., and Takamatsu, T. (2007). Cx43 mediates TGF-beta signaling through competitive Smads binding to microtubules. Mol. Biol. Cell 18, 2264-2273. doi: 10.1091/mbc.E0612-1064
Dang, X., Doble, B. W., and Kartail of connexin-43 localizes to the nucleus and inhibits cell growth. Mol. Cell. Biochem. 242, 35-38. doi: 10.1023/A:1021152709313

Dang, X., Jeyaraman, M., and Kardami, E. (2006). Regulation of connexin43-mediated growth inhibition by a phosphorylatable amino-acid is independent of gap junction-forming ability. Mol. Cell. Biochem. 289, 201-207. doi: 10.1007/s11010-0069162-2

Doble, B. W., Chen, Y., Bosc, D. G., Litchfield, D. W., and Kardami, E. (1996). Fibroblast growth factor2 decreases metabolic coupling and stimulates phosphorylation as well as masking of connexin43 epitopes in cardiac myocytes. Circ. Res. 79, 647658. doi: 10.1161/01.RES.79.4.647

Doble, B. W., Dang, X., Ping, P., Fandrich, R. R., Nickel, B. E., Jin, Y., et al. (2004). Phosphorylation of serine 262 in the gap junction protein connexin-43 regulates DNA synthesis in cell-cell contact forming cardiomyocytes. J. Cell Sci. 117, 507-514. doi: 10.1242/jcs.00889

Doble, B. W., Ping, P., and Kardami, E. (2000). The epsilon subtype of protein kinase $\mathrm{C}$ is required for cardiomyocyte connexin- 43 phosphorylation. Circ. Res. 86, 293-301. doi: 10.1161/01.RES.86.3.293

Heldin, C. H., Landstrom, M., and Moustakas, A. (2009). Mechanism of TGF-beta signaling to growth arrest, apoptosis, and epithelialmesenchymal transition. Curr. Opin. Cell Biol. 21, 166-176. doi: 10.1016/j.ceb.2009.01.021

Herrero-Gonzalez, S., Gangoso, E., Giaume, C., Naus, C. C., Medina, J. M., and Tabernero, A. (2010). Connexin43 inhibits the oncogenic activity of $\mathrm{c}-\mathrm{Src}$ in $\mathrm{C} 6$ glioma cells. Oncogene 29, 5712-5723. doi: 10.1038 /onc. 2010.299 dami, E. (2003). The carboxy-

overcome the growth inhibitory effect of $\mathrm{Cx} 43$ on cardiomyocytes is likely to depend on expression of appropriate levels of signaltransducing machinery [FGF-2 receptors, active $\mathrm{PKC} \varepsilon$, inactive phosphatase(s)] to achieve and/or sustain phosphorylation of endogenous $\mathrm{Cx} 43$ at $\mathrm{S} 262$.

\section{ACKNOWLEDGMENTS}

This work was funded (to Elissavet Kardami) by the Heart and Stroke Foundation of Manitoba, and the Canadian Institutes for Health Research (FRN 74733). Maya M. Jeyaraman had a studentship award from the Heart and Stroke Foundation of Canada. We thank Dr. Rebecca G. Wells (University of Pennsylvania School of Medicine, PA, USA) for her generous gift of adenoviral vectors expressing DN versions of Smad2 and Smad3.

Inman, G. J., Nicolas, F. J., Callahan, J. F., Harling, J. D., Gaster, L. M., Reith, A. D., et al. (2002). SB-431542 is a potent and specific inhibitor of transforming growth factor-beta superfamily type I activin receptorlike kinase (ALK) receptors ALK4, ALK5, and ALK7. Mol. Pharmacol. 62, 65-74. doi: 10.1124/mol.62.1.65

Jeyaraman, M., Tanguy, S., Fandrich, R. R., Lukas, A., and Kardami, E. (2003). Ischemia-induced dephosphorylation of cardiomyocyte connexin-43 is reduced by okadaic acid and calyculin A but not fostriecin. Mol. Cell. Biochem. 242, 129 134. doi: 10.1023/A:1021102131603

Jiang, Z. S., Padua, R. R., Ju, H., Doble, B. W., Jin, Y., Hao, J., et al. (2002). Acute protection of ischemic heart by FGF-2: involvement of FGF2 receptors and protein kinase C. Am. J. Physiol. Heart Circ. Physiol. 282, H1071-H1080.

Jiang, Z. S., Srisakuldee, W., Soulet, F., Bouche, G., and Kardami, E. (2004). Non-angiogenic FGF-2 protects the ischemic heart from injury, in the presence or absence of reperfusion. Cardiovasc. Res. 62, 154-166. doi: 10.1016/j.cardiores.2004.01.009

Johnstone, S. R., Kroncke, B. M., Straub, A. C., Best, A. K., Dunn, C. A., etal. (2012). MAPK phosphorylation of connexin 43 promotes binding of cyclin E and smooth muscle cell proliferation. Circ. Res. 111, 201-211. doi: 10.1161/CIRCRESAHA.112.272302

Kardami, E. (1990). Stimulation and inhibition of cardiac myocyte proliferation in vitro. Mol. Cell. Biochem. 92, 129-135. doi: 10.1007/ BF00218130

Kardami, E., Banerji, S., Doble, B. W., Dang, X., Fandrich, R. R., Jin, Y., et al. (2003). PKC-dependent phosphorylation may regulate the ability of connexin 43 to inhibit DNA synthesis. Cell Commun. Adhes. 10, 293-297.
Kardami, E., Dang, X., Iacobas, D A., Nickel, B. E., Jeyaraman, M. Srisakuldee, W., et al. (2007). The role of connexins in controlling cell growth and gene expression. Prog. Biophys. Mol. Biol. 94, 245-264. doi: 10.1016/j.pbiomolbio.2007.03.009

Massague, J. (2000). How cells read TGF-beta signals. Nat. Rev. Mol. Cell Biol. 1, 169-178. doi: 10.1038/ 35043051

Massague, J., and Wotton, D. (2000). Transcriptional control by the TGFbeta/Smad signaling system. EMBO J. 19, 1745-1754. doi: 10.1093/ emboj/19.8.1745

Matsuyama, D., and Kawahara, K. (2009). Proliferation of neonatal cardiomyocytes by connexin43 knockdown via synergistic inactivation of p38 MAPK and increased expression of FGF1. Basic Res. Cardiol. 104, 631642. doi: 10.1007/s00395-009-0029-Z

Mirandola, P., Gobbi, G., Masselli, E., Micheloni, C., Di Marcantonio, D., Queirolo, V., et al. (2011). Protein kinase Cepsilon regulates proliferation and cell sensitivity to TGFlbeta of CD4 ${ }^{+}$T lymphocytes: implications for Hashimoto thyroiditis. J. Immunol. 187, 4721-4732. doi: 10.4049/jimmunol.1003258

Pasumarthi, K. B., Kardami, E., and Cattini, P. A. (1996). High and low molecular weight fibroblast growth factor-2 increase proliferation of neonatal rat cardiac myocytes but have differential effects on binucleation and nuclear morphology. Evidence for both paracrine and intracrine actions of fibroblast growth factor-2. Circ. Res. 78, 126136. doi: 10.1161/01.RES.78.1.126

Petritsch, C., Beug, H., Balmain, A., and Oft, M. (2000). TGF-beta inhibits p70 S6 kinase via protein phosphatase $2 \mathrm{~A}$ to induce G(1) arrest. Genes Dev. 14, 3093-3101. doi: 10.1101/gad.854200 Rama, A., Matsushita, T., Charolidi, N., Rothery, S., Dupont, E., and 
Severs, N. J. (2006). Up-regulation of connexin 43 correlates with increased synthetic activity and enhanced contractile differentiation in TGF-betatreated human aortic smooth muscle cells. Eur. J. Cell Biol. 85, 375-386. doi: 10.1016/j.ejcb.2005.11.007

Sanchez-Alvarez, R., Paino, T., HerreroGonzalez, S., Medina, J. M., and Tabernero, A. (2006). Tolbutamide reduces glioma cell proliferation by increasing connexin43, which promotes the up-regulation of p21 and p27 and subsequent changes in retinoblastoma phosphorylation. Glia 54, 125-134. doi: 10.1002/glia. 20363

Senyo, S. E., Steinhauser, M. L., Pizzimenti, C. L., Yang, V. K., Cai, L., Wang, M., et al. (2013). Mammalian heart renewal by pre-existing cardiomyocytes. Nature 493, 433-436. doi: 10.1038/nature11682

Sheikh, F., Hirst, C. J., Jin, Y., Bock, M. E., Fandrich, R. R., Nickel, B. E., et al. (2004). Inhibition of TGFbeta signaling potentiates the
FGF-2-induced stimulation of cardiomyocyte DNA synthesis. Cardiovasc. Res. 64, 516-525. doi: 10.1016/j.cardiores.2004.08.009

Solan, J. L., and Lampe, P. D. (2009). Connexin43 phosphorylation: structural changes and biological effects. Biochem. J. 419, 261-272. doi: 10.1042/BJ20082319

Srisakuldee, W., Jeyaraman, M. M., Nickel, B. E., Tanguy, S., Jiang, Z. S., and Kardami, E. (2009). Phosphorylation of connexin-43 at serine 262 promotes a cardiac injury-resistant state. Cardiovasc. Res. 83, 672-681. doi: $10.1093 / \mathrm{cvr} / \mathrm{cvp} 142$

Tacheau, C., Fontaine, J., Loy, J., Mauviel, A., and Verrecchia, F. (2008) TGF-beta induces connexin43 gene expression in normal murine mammary gland epithelial cells via activation of p38 and PI3K/AKT signaling pathways. J. Cell. Physiol. 217, 759-768. doi: 10.1002/jcp.21551

Uemura, M., Swenson, E. S., Gaca, M. D., Giordano, F. J., Reiss, M. and Wells, R. G. (2005). Smad2 and
Smad3 play different roles in rat hepatic stellate cell function and alphasmooth muscle actin organization. Mol. Biol. Cell 16, 4214-4224. doi: 10.1091/mbc.E05-02-0149

Waghabi, M. C., Coutinho, C. M., Soeiro, M. N., Pereira, M. C., Feige, J. J., Keramidas, M. et al. (2002). Increased Trypanosoma cruzi invasion and heart fibrosis associated with high transforming growth factor beta levels in mice deficient in alpha(2)-macroglobulin. Infect. Immun. 70, 5115-5123. doi: 10.1128/IAI.70.9.5115-5123.2002

Zhang, Y., Kanter, E. M., Laing, J. G., Aprhys, C., Johns, D. C., Kardami, E., et al. (2008). Connexin43 expression levels influence intercellular coupling and cell proliferation of native murine cardiac fibroblasts. Cell Commun. Adhes. 15, 289-303. doi: $10.1080 / 15419060802198736$

Conflict of Interest Statement: The authors declare that the research was conducted in the absence of any commercial or financial relationships that could be construed as a potential conflict of interest.

Received: 12 April 2013; accepted: 28 June 2013; published online: 19 July 2013.

Citation: Jeyaraman MM, Fandrich RR and Kardami E (2013) Together and apart: inhibition of DNA synthesis by connexin-43 and its relationship to transforming growth factor $\beta$. Front. Pharmacol. 4:90. doi: 10.3389/fphar.2013.00090 This article was submitted to Frontiers in Pharmacology of Ion Channels and Channelopathies, a specialty of Frontiers in Pharmacology.

Copyright (c) 2013 Jeyaraman, Fandrich and Kardami. This is an open-access article distributed under the terms of the Creative Commons Attribution License, which permits use, distribution and reproduction in other forums, provided the original authors and source are credited and subject to any copyright notices concerning any third-party graphics etc. 